\title{
Students’ Self-Diagnosis Using Worked-Out Examples
}

\author{
Rafi' Safadi ${ }^{1,2}$, Edit Yerushalmi ${ }^{2}$ \\ ${ }^{1}$ Department of Research and Evaluation, Academic Arab College for Education in Israel, Haifa, Israel \\ ${ }^{2}$ Department of Science Teaching, Weizmann Institute of Science, Rehovot, Israel \\ Email: rafi.safadi@gmail.com
}

Received December 30 ${ }^{\text {th }}$, 2012; revised January $30^{\text {th }}, 2013$; accepted February $14^{\text {th }}$, 2013

\begin{abstract}
Students in physics classrooms are often asked to review their solution to a problem by comparing it to a textbook or worked-out example. Learning in this setting depends to a great extent on students' inclination for self-repair; i.e., their willingness and ability to recognize and resolve conflicts between their mental model and the scientifically acceptable model. This study examined the extent to which self-repair can be identified and assessed in students' written responses on a self-diagnosis task in which they are given time and credit for identifying and explaining the nature of their mistakes assisted by a worked-out example. Analysis of $18010^{\text {th }}$ and $11^{\text {th }}$ grade physics students in private and public schools in the Arab sector in Israel showed that although most students were able to identify differences between their solution and the worked-out example that significantly affected the way they approached the problem many did not acknowledge the underlying conflicts between their interpretation and a scientifically acceptable interpretation of the concepts and principles involved. Rather, students related to the worked-out example as an ultimate template and simply considered their deviations from it as mistakes. These findings were consistent in all the classes and across all the teachers, irrespective of grade level or school affiliation. However, younger students in some classrooms also perceived the task as a communication channel to provide feedback to their teachers on their learning and the instructional materials used in the task. Taken together, the findings suggest that instructional intervention is needed to develop students' ability to self-diagnose their work so that they can learn from this type of task.
\end{abstract}

Keywords: Problem Solving; Worked-Out Example; Self-Diagnosis; Self-Repair

\section{Introduction}

Students in physics classrooms are often given worked-out examples ${ }^{1}$ of homework problems to enable them to analyze their mistakes, or as models to introduce new material in class. However, research has shown that students differ in terms of how well they are able to explain the worked-out examples to themselves, and how well they perform on subsequent transfer problems. Specifically, successful problem solvers provide more self-explanations-defined as content-relevant articulations formulated after reading a line of text that state something beyond what the sentence explicitly said (Chi et al., 1989). Moreover, there are qualitative differences in the self-explanations generated by successful and non-successful problem solvers. For example, in the context of studying a worked-out example, self-explanations produced by successful problem solvers are characterized by relating solution steps to domain principles or elaborating the application conditions of physics principles (Chi \& Vanlehn, 1991). Certain researchers have argued (Chi, 2000) that to explain how self-explanations facilitate learning, self-explanation has, in part, to involve a process of self-repair; i.e., a process of recognizing and acknowledging that a conflict exists between the scientific model conveyed by a worked-out example and the student's possibly flawed mental model, and attempting to resolve this conflict.

A variety of interventions aimed at enhancing the capacity of

${ }^{1}$ In this paper, we use the term "worked-out examples" to refer to problem solutions that the instructor distributes to students demonstrating step-by-step how to solve a problem (Clark et al., 2006: p. 190). self-explanations within the context of studying worked-out examples have been proposed and shown to foster learning outcomes (Atkinson et al., 2003; Chi et al., 1994; Renkl et al., 1998). Enhancing the capacity of self-explanations can also take place within the context of solving problems. Curriculum developers have produced instructional interventions that present students with problem situations designed to elicit intuitive ideas and encourage peer discussions in which students work in groups, suggest various approaches to solve the problem at hand, reflect on their and their peers' approaches and explain their ideas (Mazur, 1997; McDermott et al., 1998; Sokoloff \& Thornton, 2001). Such discussions can induce students to provide self-explanations. By explaining their approach to a problem out loud, and comparing it to their peers' solutions, students are encouraged to engage in self-repair through recognizing and resolving conflicts between their and their peers' mental models.

Researchers have also developed "self-diagnosis tasks" (Henderson \& Harper, 2009; Etkina et al., 2006; Yerushalmi, Singh et al., 2007) that exploit a frequent activity in physics classrooms where students are provided with worked-out examples after having done some task on their own as part of their homework, or on a quiz or exam. Instructors provide workedout examples to help their students self-diagnose their solutions by comparing their solution to the worked-out example to improve it or learn from their mistakes. However, many instructtors worry that only a few of their students indeed engage in this reflective activity (Yerushalmi, Henderson et al., 2007). They suspect that most students merely skim over the worked- 
out example rather than carefully comparing it to their own solution to learn from it. Self-diagnosis tasks modify this common classroom practice to make certain that students will reflect on their solution by providing them with time and credit for writing "self-diagnoses".

As in the case of interventions prompting students to provide self-explanations when studying worked-out examples, interventions where students review and correct their own solutions using a worked-out example are designed to generate self-explanations involving self-repair leading to changes in mental models. However research has shown that students' self-diagnosis performance is not correlated with their performance on transfer problems when they are supplied with worked-out examples (Yerushalmi et al., 2009; Mason et al., 2009). These researchers hypothesized that when students receive a workedout example they interpret the task as a comparison of the surface features of their solution to the worked-out example. Thus in their diagnosis they merely "copy paste" the procedures in the worked-out example that differ from their own solution without actually self-repairing their mental model. In this article we examine how students perceive the function of selfdiagnosis tasks, and the extent to which students involved in self-diagnosis on worked out-examples engage in self-repair.

\section{Scientific Background}

Worked-out examples in textbooks or by instructors are among the main learning and teaching resources in problem solving in physics (Maloney, 2011) (as in other subjects). They are used in different ways: a) in the first stages of skill acquisition or learning a new topic, instructors usually use worked-out examples to demonstrate how to apply principles and concepts; b) students rely on worked-out examples as aids in solving new problems throughout a course (Eylon \& Helfman, 1982; Gick \& Holyack, 1983); and c) after homework and/or tests, instructors commonly provide their students with worked-out examples as feedback on problems they were asked to solve (Yerushalmi et al., 2007). This paper deals with self-diagnostic tasks that relate to the latter case. In this context, students interact with two artifacts: a possibly deficient textual artifact which is the outcome of processes that they themselves carried out, and the worked-out example which is the product of a process that has been carried out by somebody else. To better explore self-repair that take place in this context, we first review research on learning through interaction with worked-out examples, and studies on learning through interaction with deficient solutions.

\section{Learning through Interaction with Worked-Out Examples}

In self-explaining a worked out example, the learner reads an artifact created by someone else (i.e., an expert). Thus, the text acts as a mediator between the expert's mental model and that of the learner. Chi et al. (1989) analyzed worked-out examples in standard textbooks and showed that they frequently omit information justifying the solution steps. This is important because research has documented differences between students with respect to the amount and the nature of self-explanations they generate (Chi et al., 1989; Renkl, 1997) when explaining solution steps to themselves. These studies found that students who self-explain more learn more (Chi et al., 1989), and moreover that successful learners tend to generate principle-based self-explanations (Renkl, 1997).

A variety of instructional interventions have been shown to be effective in both increasing the amount as well as the nature of self-explanations. These interventions are based on "prompting"; i.e., providing students with explicit verbal reminders to engage in the process of self-explaining (Chi et al., 1994). This can take many forms such as prompting via computer tutors (Aleven \& Koedinger, 2002; Crippen \& Earl, 2005; Hausmann \& Chi, 2002), or by embedding the reminders in the learning materials (Hausmann \& VanLehn, 2007). Principlebased prompts have been shown to be effective in inducing principle-based self-explanations (Atkinson et al., 2003).

Research has also shown that the effectiveness of students' learning from examples is affected by their design (Ward \& Sweller, 1990; Chandler \& Sweller, 1991; Chandler \& Sweller, 1992). The critical factors are whether they can direct the learner's attention appropriately and reduce cognitive load. For example, worked-out examples that include diagrams that are separate from related formulas require students to split their attention and were found to be less effective than examples that integrate these elements. Labeling the solution steps into "sub-goal" categories encourages students to generate self-explanations explicating the sub-goals related to these categories (Catrambone, 1998).

Last but not least, research has indicated that learning from worked-out examples is more effective than problem solving at the initial stages of skill acquisition (Atkinson et al., 2000; Sweller et al., 1998). Process-oriented solutions (presenting the rationale behind solution steps) are appropriate at this stage (Van Gog et al., 2008). When learners acquire more expertise, worked-out examples per se are less effective (the expertisereversal effect, Kalyuga et al., 2003). At this stage students benefit more from learning from practice problems on their own followed by isomorphic examples (Reisslein et al., 2006).

\section{Learning through Interactions with Deficient Solutions}

Research has focused on two types of deficient solutions: a) “teacher-made', and b) "student-made”.

a) "Teacher-made" deficient solutions. Studying "teachermade" mistaken solutions was found to be advantageous for learners with a high level of knowledge. By contrast, learners with poor prior knowledge benefit to some extent only if the errors in the mistaken solution are highlighted (Große \& Renkl, 2007). Activities in which students were asked to diagnose mistaken statements (i.e., explain the nature of the mistake, note what they should pay attention to in order to avoid similar mistakes in the future, and formulate a correct statement) were shown to significantly improve students' understanding of the topics addressed (Labudde et al., 1988). Another example is the PAL computer coach that employs a reciprocal-teaching strategy (Reif \& Scott, 1999) in which computers and students alternately coach each other. PAL deliberately makes mistakes mimicking common student errors and asks to be told if the student catches any mistakes.

b) "Student-made" incorrect solutions. Research on learning from student-made incorrect solutions has focused on students' performance in "self-diagnosis" (Henderson \& Harper, 2009) or "self-assessment" tasks (Etkina et al., 2006). Self-diagnosis tasks explicitly require students to self-diagnose their own solutions when given some feedback on the solution, for example in 
the form of a worked-out example.

Researchers (Cohen et al., 2008) studied students' performance in self-diagnosis tasks in the context of an algebra-based introductory course in a US college. Students were first involved in a short training session about self-diagnosis. The students then had to solve context-rich problems as part of a quiz. The following week they were each given a photocopy of their quiz solution and were asked to diagnose it with alternative external supports, one of which was a worked-out example. The results showed that students' self-diagnosis performance was better with a worked-out example than without it, but self-diagnosis performance correlated with their performance on transfer problems only when they were not supplied with worked-out examples. The authors suggested that the students compared their solution to the worked-out example in a superficial manner that did not allow them to generalize the analysis of their mistakes beyond the specific problem (Yerushalmi et al., 2009; Mason et al., 2009).

\section{Methodology}

As mentioned earlier, the process of self-repair was originnally suggested (Chi, 2000) to explain how self-explanations facilitate learning when reading a worked-out example. However, self-repair in the context of a self diagnosis task using a worked-out example differs from self-repair in the context of studying a worked-out example per se, as self diagnosis involves two written texts; i.e., the student's solution as well as the worked-out example, rather than merely the latter. Accordingly, in the self diagnosis context students are asked to identify differences between the two written texts that are related to differences between their own mental model and the scientific model underlying the worked out example.

To assess self-repair in students' written responses on a self-diagnosis task when using a worked-out example we posited that for self-repair to take place in this context students must a) identify differences between their solution and the worked-out example that are crucial to finding the correct solution to the problem. We term these "significant differences"; b) acknowledge that there is a conflict between their (possibly flawed) mental model and the scientific model conveyed by the worked-out example (i.e., conflicts underlying the identified differences); and c) try to resolve the conflict. In view of that, we examined:

1) To what extent students identify significant differences between their own solutions and the worked-out example?

2) To what extent students acknowledge and try to resolve conflicts between their mental model and the scientific model underlying the worked-out example?

To understand how students perceive the function of the selfdiagnosis task we drew on the concept of action pattern (Wertsch, 1984). When individuals carry out a specific task they operate according to a mental representation of the task involving both object representation - the way in which objects that pertain to the task setting are represented, and action patterns - the way in which the operator of the task perceives what is required. In the context of a self-diagnosis task, object representation refers to the representation of the problem situation in terms of physics concepts and principles, whereas action pattern refers to perceiving the interaction with a worked-out example as a process of identifying, clarifying and bridging differences between the instructor's and the student's representa- tion of the problem situation. Another possible action pattern is tracking visual difference between the worked-out example and the student's solution to satisfy the instructor's perceived requirements. In the present study, we looked for manifestations of such action patterns/perceptions in the way students carried out the self-diagnosis task.

Students primarily form their perceptions of physics learning in the classroom, and their perceptions of a self diagnosis task are likely to vary as a function of their specific classroom culture, which depends on various factors such as grade level, school culture, the agenda of a specific teacher, etc. For example, studies of school culture in the Arab sector in Israel portray it as highly authoritative and formal, and shaped by strong family traditions that stress values such as honor and respect for elders (Dkeidek et al., 2011; Eilam, 2002; Tamir \& Caridin, 1993). To determine whether such a group effect took place, we examined how students' perceptions of the self-diagnosis task differ across classrooms.

\section{Participants}

We examined the above questions in a group of high school students from nine schools in the Arab sector in Israel, for whom this was their first exposure to a self-diagnosis task. The classroom teachers had attended a year-long in-service professsional development workshop for high-school physics teachers from the Arab sector in Israel. The aim of the workshop was to promote teaching methods to develop students' learning skills in the context of problem-solving, in particular formative assessment tasks. As part of the workshop, a self-diagnosis task was administered by the teachers. No training took place prior to the administration of the task.

One hundred and eighty high school students taking advanced physics participated in the study. Students were drawn from classrooms differing in grade level and school affiliation. Three classes (two $10^{\text {th }}$ grade $(\mathrm{N}=39)$ and one $11^{\text {th }}$ grade $(\mathrm{N}=$ 26)) were drawn from private schools operated by the Christian church in Israel. These pluralistic schools, where Christian and Muslim students study together, target students from urban middle class families. The other classes (one $10^{\text {th }}$ grade $(\mathrm{N}=26)$ and five $11^{\text {th }}$ grade $(\mathrm{N}=89)$ ) were from state (governmental) and private schools that target a more rural and traditional population. All students had already completed or were in the final stage of studying the topic of kinematics.

\section{Data Collection}

The data for this study consisted of students' answers on this self-diagnosis task; i.e., students' problem solutions and their written self-diagnoses.

In the self-diagnosis task, students were first asked to solve a problem based on kinematics concepts as part of a quiz (see Figure 1).

This was to some extent a "context-rich" problem (Heller \& Hollbaugh, 1992) presented in a real-life context, not broken down into parts, and without any accompanying diagram. Students were provided with presentation guidelines (see Figure 1) for the problem solution to help them unravel the intertwined requirements posed by a context-rich problem. The classroom teachers confirmed that the problem was suitable for high school physics students in terms of its content and level of difficulty. The participating students, however, had only had little 
From a research station located on Mars a rocket is launched straight upward with a constant acceleration of $30 \mathrm{~m} / \mathrm{s}^{2}$ by its booster engines. The goal of the mission is to collect data about the chemical composition of the atmosphere as a function of the distance from the ground with instruments located in the rocket. The fuel used to run the engines is depleted in 25 seconds. After that, the rocket travels without engine power. As a student in NASA's "Young Scientist" project you are asked to find the maximum altitude the rocket can reach. The following data are given:

- No significant change in the free falling acceleration until the rocket reaches the maximum altitude.

- A table of measurements produced by a robot to find the free fall acceleration close to the surface of Mars. The robot released a ball. From the time of release, which is defined as $t=0$, the robot measured (by means of its time and distance sensors) the distance of the ball relative to the release point in periods of 0.04 seconds. Data were gathered by the robot's computer and they are presented in the following table:

Presentation guidelines - the problem solution should include:

Problem description: Represent the problem in physics terms: Draw a sketch, list known quantities and target variable.

Solution construction: Present the solution as a set of sub-problems. In each sub-problem write down:

$\checkmark$ The intermediate variable you are looking for,

$\checkmark$ The physics principles you'll use to find it,

$\checkmark$ The process to extract the unknown.

Check answer: Write down how you checked whether your final answer is reasonable.

\begin{tabular}{|c|c|}
\hline $\begin{array}{c}\text { Time since the } \\
\text { moment of } \\
\text { release (seconds) }\end{array}$ & $\begin{array}{c}\text { Distance relative } \\
\text { to the release } \\
\text { point (meters) }\end{array}$ \\
\hline 0.00 & 0.000 \\
\hline 0.04 & 0.003 \\
\hline 0.08 & 0.012 \\
\hline 0.12 & 0.028 \\
\hline 0.16 & 0.050 \\
\hline 0.20 & 0.078 \\
\hline
\end{tabular}

Figure 1.

Problem used in the study with guidelines for presenting a problem solution according to a problem-solving strategy.

experience solving context-rich problems, as this kind of problem is rarely found on the matriculation exam (which tends to dictate the nature of the problems presented by most teachers to their students).

Solving the problem selected for this study involved the following requirements:

a) Invoking physics concepts and expressions (i.e., kinematic expressions for the motion variables in constant acceleration along straight line) that could help analyze the motion of a rocket, as well as the experimental data related to the free fall of a ball close to the surface of Mars.

b) Applying the expressions invoked to solve the problem correctly. This included: 1) Representing the kinematics variables described in the problem statement adequately (i.e., the direction of acceleration and velocity when the rocket engine shuts down); 2) Identifying sub-problems - Recognizing the intermediate variables needed to solve the problem, such as the free fall acceleration of the ball; 3) Linking the various subproblems adequately (i.e. substituting variables resulting from one sub-problem into another); 4) Producing a graphical representation of the experimental data as a way to reduce experimental errors; 5) Analyzing the graphical representation to find the free fall acceleration of the ball.

c) Presenting the solution to the problem according to the presentation guidelines.

In the lesson following the quiz, students received a photocopy of their own solution and a worked-out example (see Figure 2). The latter was a process oriented solution (Van Gog et al., 2008) that followed the guidelines in the problem (Figure 1). Students were asked to write a self-diagnosis of their own solution, by identifying where they had gone wrong and explaining the nature of their mistakes.

Figure 3 depicts a student's solution to the problem and his attempt at self-diagnosis.

\section{Data Analysis}

We analyzed students' self-diagnoses using an analysis rubric adapted from a previous study (Mason et al., 2008) (Table 1).

The rubric assesses students' performance when solving the problem at hand, as well as their performance in diagnosing deficiencies they had in solving the problem.

To represent whether the students' self diagnosis addressed possible conflicts between their mental models and the scientific model underlying the worked-out example we entered another code in the rubric (i.e., in the RSD column in Table 1). Significant differences that were accompanied by acknowledgment with/without partial or complete resolution of a conflict were coded 1 and those that had no acknowledgement were coded 2. For brevity, hereafter we denote such statements as "accompanied by ARC (Acknowledge, Resolve Conflict)" (Table 1).

Table 1 demonstrates also how we used the rubric when evaluating the work of specific student S5 whose solution and self-diagnosis are presented in Figure 3.

The analyses above were all based on classifying the data into categories, using students' statements conveying a single diagnostic idea as the unit of analysis. A "diagnostic idea” was defined as referring to the content of the solution or to the student's perceptions of the self-diagnosis task. A diagnostic idea might be part of a sentence, or composed of several sentences.

To assess inter-rater reliability, two researchers applied this analysis grid to $20 \%$ of the data. Before discussion, inter-rater reliability was $75 \%$. All disagreements were discussed until full agreement was reached.

\section{Findings}

\section{Manifestation of Self-Repair in Students' Written Self-Diagnoses}

Since every student made at least one significant mistake in solving the problem, all of them could potentially pinpoint significant differences. In fact almost all (90\%) identified at least one significant difference between their solution and the worked-out example, as shown in the quotes below where students acknowledged that they did not invoke an appropriate equation: "I calculated the height at the first stage incorrectly; I should have used the equation of position vs. time for constant acceleration, rather than for constant speed" (S41) and "I solved the problem using the wrong equation: $\mathrm{y}=\mathrm{y}_{\mathrm{o}}+\mathrm{v}_{\mathrm{o}} \mathrm{t}+0.5 \mathrm{at} \mathrm{t}^{2}$, (S82).

However, many significant differences identified by the re- 


\begin{abstract}
1. Description of the problem
During the launch the rocket moves along a vertical straight line. The position axis $y$ is chosen so that its origin is on the ground at the launching point and directed positively upward. The motion has two sections: 1) the first section OA, lasting 25 seconds from the moment of launch until the fuel is used up - motion with constant acceleration along a straight line, from $\mathrm{v}_{0}=0$ up to a specific velocity $\mathrm{v}_{\mathrm{A}}$ straight upward, and 2) the second section $\mathrm{AB}$, after the fuel is used up - slowed down motion, with the free-fall acceleration on Mars - the rocket continues moving upwards at a decreasing velocity until it stops. This motion is a straight upward projectile motion, with a constant acceleration $\mathrm{a}_{2}=-\mathrm{g}$, from a velocity $\mathrm{v}_{\mathrm{A}}$ to a velocity $\mathrm{v}_{\mathrm{B}}=0$.

Knowns: Initial speed: $\mathrm{v}_{0}=0$. Duration of the first segment $\Delta \mathrm{t}=25 \mathrm{~s}$. Acceleration in the first segment (the accelerated stage) $a_{1}=30 \mathrm{~m} / \mathrm{s}^{2}$. After the fuel is used up the rocket continues moving upwards until it stops: $v=0$ at the targeted maximum altitude.

Target quantity: the maximum altitude $\mathrm{y}_{\mathrm{B}}$ when its velocity is $\mathrm{v}_{\mathrm{B}}=0$.

2. Constructing the solution
\end{abstract}

Solution plan: The total displacement is equal to the sum of the two displacements in the segments $\mathrm{AB}$ and $\mathrm{OA}$. You can calculate $\triangle \mathrm{y}_{\mathrm{AB}}$ by means of the expression for the displacement given the initial and the final velocities in straight line motion with constant acceleration. For this purpose you need to know the initial velocity $\mathrm{v}_{\mathrm{A}}$ and the acceleration. However, $\mathrm{v}_{\mathrm{A}}$ is the final velocity in the OA segment and can be calculated using the expression for the velocity in straight line motion with constant acceleration given the acceleration and the initial velocity. To find $\Delta y_{O A}$ you can use the expression of the displacement in straight line motion with constant acceleration.

\title{
Execution of plan:
}

a: Find the displacement $\Delta y_{\mathrm{OA}}$ for the $\mathrm{l}^{\text {st }}$ segment using the expression for displacement in straight line motion with constant acceleration:

$$
\Delta y_{O A}=V_{O} t+\frac{1}{2} a_{1} t^{2} \Rightarrow \Delta y_{1}=0 \cdot 30+\frac{1}{2} 30 \cdot 25^{2}=9375 \mathrm{~m}
$$

b: Find the final velocity in the $1^{\text {st }}$ segment, $v_{A}$, using the expression for velocity in straight line motion with constant acceleration:

$$
\mathrm{v}_{\mathrm{A}}=\mathrm{v}_{0}+\mathrm{a}_{1} \mathrm{t} \Rightarrow \mathrm{v}_{\mathrm{A}}=0+30 \cdot 25=750 \frac{\mathrm{m}}{\mathrm{s}}
$$

c: Calculation of the free-fall acceleration on Mars based on the experiment outcomes shown in the table. The formula describing the distance of the falling ball from its point of release as a function of time is the square function: $\mathrm{y}=\mathrm{gt}^{2} / 2$ when $\mathrm{y}$ is measured in relation to a vertical axis starting at the point of release of the ball and directed positively downward. According to this formula, the graph of $y$ as a function of $t$ is a parabola with which makes it awkward to find acceleration g. To get a straight line graph we represent the distance of the fall $\mathrm{y}$ as a function of time squared $\mathrm{t}^{2}$. The slope of this graph will be $\mathrm{g} / 2$.

According to the linear fit equation, the slope is $1.95 \mathrm{~m} / \mathrm{s}^{2} \Rightarrow$ the free fall acceleration on Mars is: $\mathrm{g} / 2=1.95 \rightarrow \mathrm{g}=3.9 \mathrm{~m} / \mathrm{s}^{2}$. The rocket's acceleration in the $2^{\text {nd }}$ segment of its launch is $\mathrm{a}_{2}=-\mathrm{g}=-3.9 \mathrm{~m} / \mathrm{s}^{2}$, relative to the $\mathrm{y}$ axis described at the beginning of the solution.

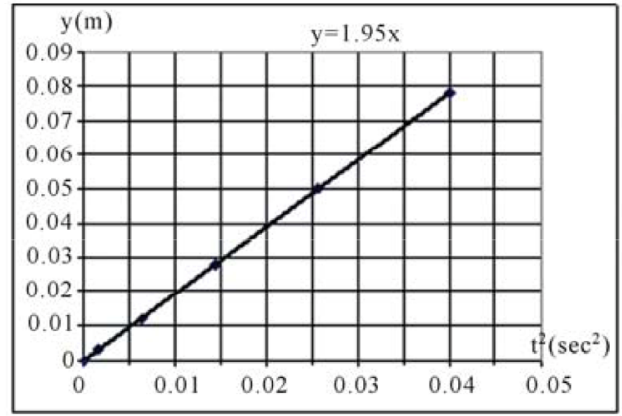

Graph of the distance of the fall as a function of time squared $y\left(t^{2}\right)$

d: Find the displacement $\Delta \mathrm{y}_{\mathrm{AB}}$ for the $2^{\text {nd }}$ segment of the motion using the expression relating the displacement, the initial velocity and the final velocity in straight line motion with constant acceleration:

$$
\mathrm{V}_{\mathrm{B}}^{2}=\mathrm{V}_{\mathrm{A}}^{2}+2 \mathrm{a}_{2} \Delta \mathrm{y}_{\mathrm{AB}} \Rightarrow \Delta \mathrm{y}_{\mathrm{AB}}=\frac{\mathrm{V}_{\mathrm{B}}^{2}-\mathrm{V}_{\mathrm{A}}^{2}}{2 \mathrm{a}_{2}} \Rightarrow \Delta \mathrm{y}_{\mathrm{AB}}=\frac{0-750^{2}}{2 \cdot(-3.9)} \approx 72,115 \mathrm{~m}
$$

e: Calculation of the maximum altitude the rocket can reach: $y_{B}=\Delta y_{O A}+\Delta y_{A B} \Rightarrow y_{B} \approx 9375+72115=81,490 m$

\section{Reasonability check of the final result}

unit check - displacement expression in the second section:

$$
\mathrm{y}_{\mathrm{AB}}=\frac{\mathrm{v}_{\mathrm{B}}^{2}-\mathrm{v}_{\mathrm{A}}^{2}}{2 \mathrm{a}_{2}} \Rightarrow\left[\Delta \mathrm{y}_{\mathrm{AB}}\right]=\frac{\left(\frac{\mathrm{m}}{\mathrm{s}}\right)^{2}-\left(\frac{\mathrm{m}}{\mathrm{s}}\right)^{2}}{\frac{\mathrm{m}}{\mathrm{s}^{2}}}=\frac{\left(\frac{\mathrm{m}}{\mathrm{s}}\right)^{2}}{\frac{\mathrm{m}}{\mathrm{s}^{2}}}=\mathrm{m}
$$

\section{Figure 2.}

The instructor's solution used in the study, aligned with guidelines.

searchers were missing from students self-diagnoses (e.g. only one-third of the students identified more than half of the differences that the researchers labeled as significant). Worse, many students (40\%) mentioned differences that had no bearing on finding the solution to the problem such as superficial differences between their solution and the worked-out example such as: "I did not provide a detailed verbal description throughout the solution" (S92).

Moreover, most students did not accompany their self-diagnoses with ARCs-Acknowledgment, and in the best case Resolution of Conflict; hence their self-diagnosis did not indicate engagement in self-repair. The citations above are good examples in that they do not include further discussion as to why the equations invoked were not appropriate (i.e., student S82 could have explained that as time was not one of the knowns in the problem statement, the equation she used was not useful). An example of a statement that does reflect ARC is the following: "I made a mistake in calculating the acceleration due to the gravity on Mars. I used only 1 point from the table and this resulted in a larger inaccuracy. I should have plotted position vs. time, namely $\mathrm{y}\left(\mathrm{t}^{2}\right)$ ” (S153). This student, as well as realizing what was wrong (using only one empirical data point to calculate acceleration), also explained why it was wrong (it increases the inaccuracy). In total, 15 (8\%) students provided ARCs.

We next examined whether there were differences between the various sub-categories described in Table 1 with respect to the students' ability to identify significant differences and provide ARCs. The results are presented in Table 2.

The problem did not challenge students in terms of the "In 


\section{R. SAFADI, E. YERUSHALMI}

Table 1.

The analysis rubric. The rubric is applied to the work of specific student S5 (shown in Figure 3) that had no mistakes in the "Invoking" category (RDS = "+"; SDS= "×”; "RSD" = "NA"). In the "Applying” category, this student mistakenly (see mistake 3 in Figure 3) identified the direction of the acceleration when the rocket engine shuts down and identified this mistake in his self-diagnosis (note d). Even though the student did not clearly articulate the nature of his misunderstanding, we believe that he acknowledged it, thus providing a partial ARC (RDS = "-"; SDS = "-"; "RSD" = "1. $+")$.

\begin{tabular}{|c|c|c|c|c|c|}
\hline & & Sub-categories & RDS & SDS & RSD \\
\hline \multirow{2}{*}{ 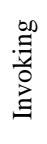 } & \multicolumn{2}{|c|}{ Kinematic equations for constant acceleration in straight line motion required to analyze the motion of the rocket } & + & $\times$ & $\begin{array}{l}\text { 1. NA } \\
\text { 2. NA }\end{array}$ \\
\hline & \multicolumn{2}{|c|}{$\begin{array}{c}\text { Kinematic equations for constant acceleration in straight line motion required to analyze the free fall of a ball near the } \\
\text { surface of Mars }\end{array}$} & + & $\times$ & $\begin{array}{l}\text { 1. NA } \\
\text { 2. NA }\end{array}$ \\
\hline \multirow{4}{*}{$\frac{\infty}{\stackrel{\infty}{\infty}}$} & & Representing kinematic variables described in the problem statement adequately & - & - & $\begin{array}{c}1 .+ \\
2 .\end{array}$ \\
\hline & $\begin{array}{l}\text { acceleration in straight line } \\
\text { motion required to find the rocket's }\end{array}$ & Identifying the entire set of required sub-problems & + & $\times$ & $\begin{array}{l}\text { 1. NA } \\
\text { 2. NA }\end{array}$ \\
\hline & motion varıables & Adequately linking data acquired in one sub-problem to another sub-problem & + & $\times$ & $\begin{array}{l}\text { 1. NA } \\
\text { 2. NA }\end{array}$ \\
\hline & $\begin{array}{l}\text { Kinematic equations for finding } \\
\text { constant acceleration given } \\
\text { experimental data }\end{array}$ & Representing the experimental data graphically & - & $x$ & $\begin{array}{l}\text { 1. - } \\
\text { 2. - }\end{array}$ \\
\hline
\end{tabular}

Legend: The sub-categories column reflects the specific principles and concepts required to be invoked and applied to solve the problem. Students' work is evaluated in three ways: RDS column - the researcher's diagnosis of the student's quiz solution (we assign “+” if a student carries out some subcategory correctly and “-” if it is incorrect). SDS column — the student's self-diagnosis of his/her solution interpreted in terms of the analysis rubric (if a student diagnoses a mistake we assign "-” to reflect how the student assessed his/her solution. If a student does not refer to some category we assign " $\times$ ”). RSD column—researcher's judgment of this student's self-diagnosis based on comparison of the researchers' and the student's diagnosis of the student's solution (we assign "+” if a student correctly identifies a mistake; “-” if the student fails to identify a mistake or identifies it incorrectly; and "NA" if it is reasonable not to address some subcategory (i.e., if the student did not make a mistake in the solution (RDS marked “+”) and did not refer to it in his/her self-diagnosis (SDS marked “×”)); “1” = significant differences accompanied by ARC (Acknowledge, Resolve Conflict); "2" = significant differences not accompanied by ARC; NA = not applicable.

Table 2.

Students' distribution into sub-categories of significant differences, with and without ARC.

\begin{tabular}{|c|c|c|c|c|}
\hline & & Sub-categories & $\begin{array}{l}\text { Having deficiencies } \\
\% \text { out of total; \# of students }\end{array}$ & $\begin{array}{l}\text { Realizing deficiencies } \\
\% \text { out of those having defi- } \\
\text { ciencies; \# of students }\end{array}$ \\
\hline \multirow{2}{*}{$\begin{array}{l}\stackrel{\infty}{\Xi} \\
: \\
:\end{array}$} & \multicolumn{2}{|c|}{$\begin{array}{l}\text { Kinematic equations for constant acceleration in straight line motion required to analyze the } \\
\text { motion of the rocket }\end{array}$} & $3 \% ; 5$ & $\begin{array}{l}\text { 1. } 40 \% ; 2 \\
\text { 2. } 60 \% ; 3\end{array}$ \\
\hline & \multicolumn{2}{|c|}{$\begin{array}{l}\text { Kinematic equations for constant acceleration in straight line motion required to analyze the } \\
\text { free fall of a ball near the surface of Mars }\end{array}$} & $2 \% ; 4$ & $\begin{array}{l}\text { 1. } 25 \% ; 1 \\
\text { 2. } 75 \% ; 3\end{array}$ \\
\hline \multirow{5}{*}{$\stackrel{\infty}{\stackrel{\infty}{\overbrace{2}}}$} & \multirow{3}{*}{$\begin{array}{l}\text { Kinematic equations for } \\
\text { constant acceleration in straight } \\
\text { line motion required to find the } \\
\text { rocket's motion variables }\end{array}$} & $\begin{array}{l}\text { Representing kinematic variables described in the } \\
\text { problem statement adequately }\end{array}$ & $24 \% ; 43$ & $\begin{array}{l}\text { 1. } 3 \% ; 2 \\
\text { 2. } 30 \% ; 12\end{array}$ \\
\hline & & Identifying the entire set of required sub-problems & $43 \% ; 77$ & $\begin{array}{l}\text { 1. NA } \\
\text { 2. } 33 \% ; 26\end{array}$ \\
\hline & & $\begin{array}{l}\text { Adequately linking data acquired in one sub-problem to } \\
\text { another sub-problem }\end{array}$ & $40 \% ; 72$ & $\begin{array}{c}\text { 1. NA } \\
\text { 2. } 50 \% ; 36\end{array}$ \\
\hline & \multirow{2}{*}{$\begin{array}{l}\text { Kinematic equations for } \\
\text { finding constant acceleration } \\
\text { given experimental data }\end{array}$} & Representing the experimental data graphically & $82 \% ; 148$ & $\begin{array}{l}\text { 1. } 7 \% ; 10 \\
\text { 2. } 46 \% ; 68\end{array}$ \\
\hline & & $\begin{array}{l}\text { Calculating the acceleration based on the graphical } \\
\text { representation }\end{array}$ & $18 \% ; 32$ & 2. $57 \% ; 18$ \\
\hline
\end{tabular}

Legend: "1" = significant differences accompanied by ARC (Acknowledge, Resolve Conflict); "2" = significant differences not accompanied by ARC; NA = not applicable. 


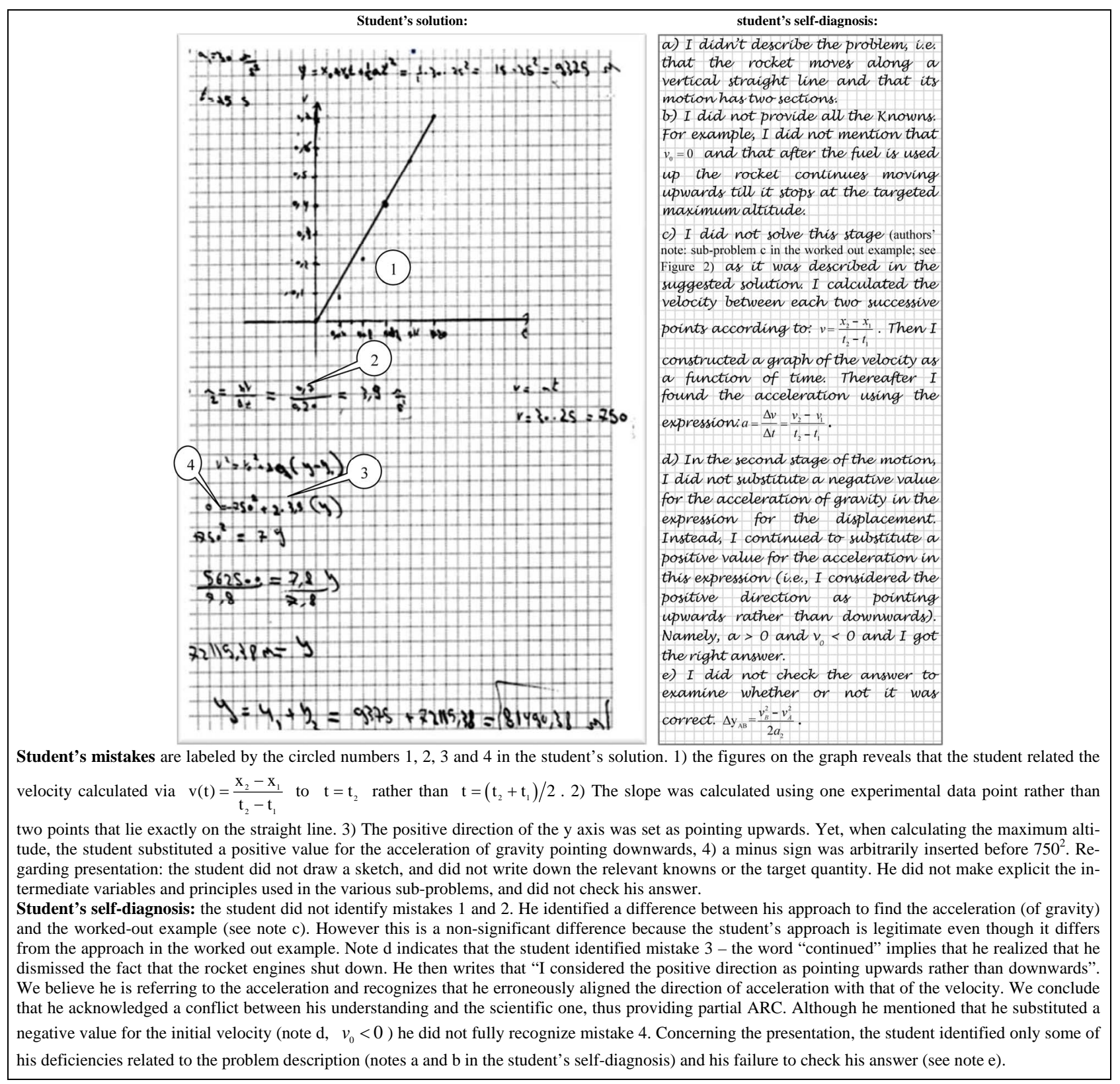

Figure 3.

A sample solution and self-diagnosis provided by one of the students (S5).

voking” category. Only nine students (see Table 2) had difficulties and all of them realized their mistakes. As the workedout example makes clear, it was reasonable to expect that given the explicit manner in which principles were referred to in the various sub-problems, students would recognize the principles missing in their own solution. However, only three of the students (one-third of the group) provided ARCs (i.e., most students did not try to explain why the equations invoked were not appropriate).

The situation was different regarding "Applying”: all the students made at least one mistake in their applications; only about half of them identified their mistakes and very few of these generated ARCs.

In the "Applying" category students stumbled into two widespread difficulties. The first relates to the representation of kinematics variables described in the problem statement. Once the rocket engine shuts down, the only force acting upon the rocket is the force of gravity; hence, the acceleration should point downwards. Yet about a quarter of the students identified the direction of acceleration as pointing upward, possibly because when the rocket engine shuts down the velocity is still pointing upwards. It is well known that students expect that an object should move in the same direction as the force acting upon it (Viennot, 1979; Halloun \& Hestenes, 1985) and that the velocity and the acceleration should thus be in the same direction. The following quote captures a diagnosis that indicates the student is aware of having misinterpreted the situation: "In the second stage of the motion, I did not substitute a negative value 
for the acceleration of gravity" (S109). This student recognized her mistake in substituting a positive value for the acceleration of gravity rather than a negative one. However, the student did not articulate an ARC (for example, by explaining what made her choose the direction of acceleration the way she did, possibly aiming to align the direction of acceleration with that of the velocity), either because she did not realize that she was required to do so, or because it was beyond her ability. In fact, only a third of the students who made this kind of mistake recognized it in their self-diagnosis and only two students provided partial ARCs (see Table 2).

The second difficulty relates to representing experimental data graphically and analyzing the graph to find the free fall acceleration. Most of the students failed to recognize the utility of representing the experimental data graphically to improve the precision of their results. Some students refrained from producing a graphical representation altogether. Instead, they relied on one or two empirical data points to calculate the acceleration (50\%); others produced an inadequate graphical representation (32\%) - these students plotted the distance y against the time $t$ and got a parabola, dismissing the fact that plotting $y$ as function of $\mathrm{t}^{2}$ would result in a straight line, and would have enabled them to find the acceleration from the slope of this graph that equals $\mathrm{g} / 2$. Of those students who did provide an adequate graph, none were able to analyze it appropriately (18\%). Similar to their peers who did not come up at all with a graph, these students' most frequent mistake was relying on one or two empirical data points to calculate the acceleration rather than from the slope of the graph.

Since the graph was a dominant visual element in the worked-out example, it would seem that self diagnosing a missing or inadequate graph would be straightforward. The students did better in recognizing their mistakes in this area than in others but they did not do well in providing ARCs. About half of the students who did not provide a graph or provided an inadequate one realized their mistakes, and only ten students (7\%) provided diagnoses with ARCs. Similarly, a little more than half of the students (57\%) noticed that they used empirical data points rather than their graph to calculate the acceleration of gravity, but none of them provided ARCs.

The following quote: "I did not plot a graph at all” (S136) represents a frequent diagnosis of this kind. The student merely mentioned the omission, but offered no explanation indicating he understood why he should have used a graph rather than one or two experimental data points. The following quote illustrates a diagnosis involving an ARC: "My mistake was that I used a graph of position vs. time, in which one cannot find the exact acceleration as it is a parabola. I should have used position vs. time squared as it results in a linear function that can be used to find the slope accurately... To find the acceleration you have to plot the slope in between the points (averaging the points) and check all the data in the table" (S30).

The other aspects of applying the kinematic equations to find the rocket's motion variables involved a) identifying the subproblems required to get the correct solution and b) adequately linking data from one sub-problem to another sub-problem. These aspects do not involve conflicts between students' conceptual understanding and the scientific model. One would expect that most students would be able to self-diagnose these two components, as the worked-out example made a visual distinction between the various sub-problems to prompt stu- dents to notice these kinds of differences between the two solutions. For example, a student wrote "Sub-problems d' and e' are missing” (S14). Unfortunately, only half of the students who made errors realized they had made mistakes (see Table 2).

To summarize, students did better in noticing significant differences related to Invoking as compared to Applying; although all the students who had deficiencies in invoking some princeples identified that their solution was missing in this respect, only one third to one half did so in terms of application. Here, they did better in recognizing significant differences related to visually prominent features in the worked-out example. In general the generation of ARCs was poor, but it was better in terms of Invoking. Furthermore, more students provided ARCs that were related to visually prominent features.

\section{Students' Perceptions of the Function of the Self-Diagnosis Task}

The simplest explanation why most students did not provide ARCs is that they were not able to articulate the fundamental nature of their mistakes. Alternatively, students may not have understood that the function of the self-diagnosis task is to identify, clarify and bridge differences between the instructor's and the student's understanding of physics concepts and principles, and that they were required to provide ARCs. This interpretation is supported by other statements students made that could not be categorized as "significant differences" (with or without ARCs). These statements focused on non-significant differences, such as the order of sub-problems in the student's example compared to the worked-out example or reflected students' opinions about the artifacts used in the self-diagnosis task or the requirements posed by the problem.

These kinds of statements provide a resource for identifying “action patterns” (Wertsch 1984); i.e., students' perceptions of what they are required to do in the self-diagnosis task. Here we employed a bottom-up approach by reading and identifying common themes in the students' statements. The emerging categories and the distribution of students' statements in these categories are shown in Table 3.

First we looked at the group of 72 students (40\%) who referred to differences that the researchers did not categorize as significant to finding the correct solution to the problem. Half of these students referred to deficiencies in their solution in a

Table 3.

Students' distribution into categories related to perceptions of the task.

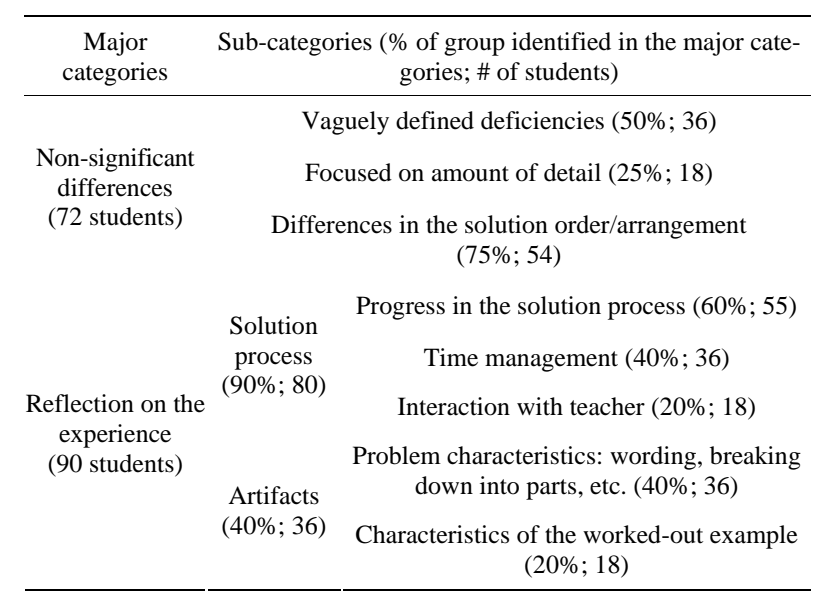


vague, nonspecific manner, such as: "All the answers were wrong. I just knew the value of gravity" (S42). Most of these students related to the worked-out example as the ultimate template by identifying external deviations from it as flaws or weaknesses in their solutions. Eighteen students referred to the extent to which their solution was detailed relative to that of the worked-out example: "I did not provide a detailed verbal description throughout the solution" (S92); and fifty four of them referred to the order of sub-problems tackled in the student's solution relative to that in the worked-out example: "I found the final velocity of the first stage only in a later step” (S82).

Half of the students reflected on their experience in carrying out the task rather than focusing on the content of the solution, making use of the task of self-diagnosis as an outlet, a way in which the students could share their experiences with the instructor (see "Reflection on the experience" category in Table 3). Almost all of them attended to the solution process. Some, for example, reflected on their progress in this process: "It became clear to me that my solution up to the stage I got to was right. However, I couldn't continue the quiz” (S43). Others addressed time management difficulties: "I spent a lot of time describing the problem" (S43) or reflected on the interaction with their teachers in the course of solving the problem: "Concerning the unfortunate graph that I drew, it was just to provide a graph as the teacher emphasized the need for a graph" (S166).

Almost half (40\%) of the students who reflected on their experience also expressed opinions regarding the artifacts used in the task, either by commenting on the challenging requirements of the target problem: "The problem is not broken down into parts. This means you have to understand a lot of things at once. Also, we are not familiar with this kind of problem” (S166) or expressing their opinion regarding the longer and detailed nature of the worked-out example: "To some extent the sample solution is long" (S174) and "The instructor's solution is very complicated, and I did not understand it” (S164). "Contextrich” problems are indeed not commonplace in physics textbooks used in Israeli high schools, since these types of problems are only rarely found on the matriculation exam.

Last, we examined how students' perceptions of the self-diagnosis task differed across classrooms.

Table 4 presents the students' distributions into the categories: 1) "Provided ARCs", 2) “Addressed non-significant differences", and 3) "Reflection on the experience" for each of the nine classes involved in the study.

Only a small number of students provided ARCs in each class (maximum three students) irrespective of grade level or school affiliation. While the classrooms varied significantly in the percentage of students who addressed non-significant differences (from $27 \%$ to $75 \%$ ) the disparities could not be attributed to grade level or school affiliation. On the other hand, students' answers in the "Reflection on the experience" category varied as a function of grade level and school affiliation. In particular, in $10^{\text {th }}$ grade classrooms affiliated with pluralistic schools, the self-diagnosis task served as a communication channel between students and their teachers to provide feedback on their learning and on the instructional materials used in the task, rather than only as a tool for self-repairing students' misinterpretations related to the problem at hand. Possibly teachers working with younger students in these schools, are more open to such communication.
Table 4.

Students' distribution into main categories for each class.

\begin{tabular}{|c|c|c|c|c|c|}
\hline 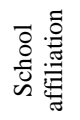 & $\begin{array}{l}\text { Grade } \\
\text { level }\end{array}$ & Class & $\begin{array}{l}\text { Provided } \\
\text { ARCs }\end{array}$ & $\begin{array}{c}\text { Addressed } \\
\text { non-significant } \\
\text { differences }\end{array}$ & $\begin{array}{l}\text { Reflection on } \\
\text { the } \\
\text { experience }\end{array}$ \\
\hline \multirow{4}{*}{ 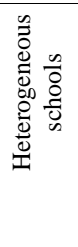 } & \multirow{4}{*}{$\begin{array}{c}10^{\text {th }} \\
\text { grade } \\
11^{\text {th }} \\
\text { grade } \\
10^{\text {th }} \\
\text { grade }\end{array}$} & $\mathrm{A}(\mathrm{N}=16)$ & $6 \%$ & $50 \%$ & $88 \%$ \\
\hline & & $\mathrm{B}(\mathrm{N}=23)$ & $9 \%$ & $39 \%$ & $100 \%$ \\
\hline & & $\mathrm{C}(\mathrm{N}=26)$ & $8 \%$ & $31 \%$ & $50 \%$ \\
\hline & & $\mathrm{D}(\mathrm{N}=26)$ & $8 \%$ & $27 \%$ & $65 \%$ \\
\hline \multirow{5}{*}{ 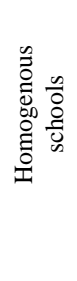 } & \multirow{5}{*}{$\begin{array}{l}11^{\text {th }} \\
\text { grade }\end{array}$} & $\mathrm{E}(\mathrm{N}=12)$ & $9 \%$ & $75 \%$ & $50 \%$ \\
\hline & & $\mathrm{F}(\mathrm{N}=15)$ & - & $53 \%$ & $40 \%$ \\
\hline & & $G(N=20)$ & $15 \%$ & $35 \%$ & $35 \%$ \\
\hline & & $\mathrm{H}(\mathrm{N}=11)$ & $10 \%$ & $73 \%$ & $18 \%$ \\
\hline & & $\mathrm{I}(\mathrm{N}=31)$ & $9 \%$ & $52 \%$ & $16 \%$ \\
\hline
\end{tabular}

\section{Summary and Discussion}

It is common practice in physics classrooms to provide students with worked-out examples after they have attempted to solve a problem on their own (i.e., homework, quiz or exam) to encourage them to compare their solutions to the worked-out example and self-diagnose their mistakes-i.e. identify where they went wrong, explain their mistakes and learn from them. In this study we examined how students self-diagnose their solutions when given time and credit for writing "self-diagnoses”, aided by worked-out examples. In particular we studied a) the extent to which students' self-diagnosis when they are aided with worked-out examples indicates engagement in self-repair, and b) students' perceptions of what they are expected to do in such a self-diagnosis task. Following Chi (2000), we differentiated between two stages of self-repair. This involved a first stage in which students identified significant differences (i.e., differences between their solutions and the worked-out example that were judged by the researchers as significant to get the correct solution), and a second stage in which students acknowledged a conflict between their understanding and the scientific model, and in the best case, were able to partially or completely resolve this conflict (i.e., provided ARCs).

We found that almost all of the students identified at least one significant difference. However, most of the students did not provide ARCs. Specifically the first stage of self-repair took place, but the second stage did not occur, or at least was not articulated. Moreover, when students self-diagnosed the various aspects of the "Applying" category, where they made the vast majority of their mistakes, at best half of those who had deficiencies identified their significant differences. This result might suggest that the self-diagnosis task did not provide an opportunity to self-repair deficiencies in the students' understanding of related concepts and principles. Furthermore, we found that at least half of the significant differences that students identified were related to visually prominent elements in the worked-out example (such as the graph). It is possible that students merely skimmed over the worked-out example and simply pinpointed obvious elements. Also, almost half of the students focused on non-significant differences by relating to 
the worked-out example as an ultimate template and simply considering their deviations from it as mistakes. These findings were consistent in all the classes and with all the teachers who participated in the study, irrespective of grade level or school affiliation. Thus we conjecture that the majority of the students did not experience self-repair processes when they engaged in self-diagnosis via the worked-out example. This conclusion is consistent with previous research findings that students' selfdiagnosis performance did not correlate with their performance on transfer problems when they were aided in a self-diagnosis task by a worked-out example (Yerushalmi et al., 2009; Mason et al., 2009). This is because the students' process of diagnosing their solution did not incorporate acknowledging and resolving conflicts (ARCs), and hence did not result in self-repair and transfer.

One possible explanation for these results is that the students did not realize that the function of the self-diagnosis task was to identify, clarify and bridge differences between the instructor's and their understanding of physics concepts and principles, and that they were required to provide ARCs. Bereiter \& Scardamalia (1989) use the term "intentional learning" to refer to "processes that have learning as a goal rather than an incidental outcome” (p. 363). For self-repair to take place in the context of a self-diagnosis task, students should perceive learning as the goal of this experience and deliberately reflect on their interpretation of concepts and the principles involved in the solution. Our results suggest that students did not approach the task in an intentional manner. The dominant listing of non-significant differences suggests that many students did not make the distinction between significant vs. non-significant differences as regards learning when self-diagnosing their work. The limited occurrences of ARCs suggest that students perceived learning from the worked example merely as a comparison and identification of differences between the worked-out example and their own solution, and not as an artifact enabling reflection and refinement of ideas.

It might be claimed that these perceptions are the outcome of an authoritative classroom culture as is known to be the case in Arab society in Israel (Tamir \& Caridin, 1993; Dkeidek et al., 2011; Eilam, 2002). In an authoritative classroom culture one would expect a dominance of epistemological beliefs including notions that knowledge in physics should come from a teacher or authority figure rather than be independently constructed by the learner. Such an outlook would foster students' tendencies to refer to anything the teacher produces, such as a worked-out example, as the ultimate template and hence devote their unproductive attention to non-significant differences. However, similar beliefs have been documented to be widespread in other cultural contexts as well. For example, in the Maryland Physics Expectations (MPEX) survey of epistemological beliefs (Redish et al., 1998) that involved 1500 students in introductory calculus-based physics courses from six colleges and universities in the US, $40 \%$ - $60 \%$ of the students in each institution expressed the epistemological belief that knowledge in physics should come from an authoritative source such as an instructor or a text rather than be independently constructed by the learner.

Our findings indicate that providing time, credit and supportive resources for self-diagnosis in the form of a worked-out example does not guarantee learning in this context. Teachers need to help students realize that identifying significant differ- ences between the worked-out example and their own solution serves as groundwork for subsequent learning process, and aids in acknowledging and resolving the underlying conflicts between their interpretations and a scientifically acceptable interpretation of the concepts and principles involved. To do so, teachers need to address the following key facets: a) developing in students a perception of problem solving as an intentional learning experience; b) developing students' ability to recognize the deep structure of worked-out examples; c) developing in students diagnostic skills.

a) Developing in students a perception of problem solving as an intentional learning experience. Elby (2001) developed an epistemology-focused course that was found to help students develop more positive attitudes toward the meaningfulness of mathematical equations and the constructive nature of learning. Our findings suggest that incorporating instructional practices and curricular elements from an introductory physics course could improve students' learning in the context of self-diagnosis tasks.

b) Developing students' ability to recognize the deep structure of worked-out examples: As mentioned earlier, studies have shown that students can be encouraged to provide more self-explanations when reading worked-out examples by engaging them in activities where they are "prompted" to selfexplain (Chi et al., 1994) by computerized training systems (Aleven \& Koedinger, 2002; Crippen \& Earl, 2005; Hausmann \& Chi, 2002), or by prompts embedded in the learning materials (Hausmann \& VanLehn, 2007). Atkinson, Renkl and Merrill (2003) showed that principle-based prompts are effective in inducing the principle based self-explanations characteristic of successful learners Renkl (1997). Future research could examine the effect of training providing principle-based self-explanations on students' performance in self-diagnosis tasks.

c) Developing diagnostic skills: It has been shown (Schwartz \& Martin, 2004) that contrasting cases can help learners develop more differentiated knowledge, which can guide their subsequent interpretation and learning from other learning resources, for example, as in the case cited, from a lecture. By analogy, activities that present students with incorrect solutions, and require them to explain the error with reference to principles requires students to distinguish scientifically acceptable interpretations of concepts from the lay interpretation, thereby prompting them to focus on those features of a concept needed to interpret it accurately. Awareness of such features could in turn support learning from other resources, for example, a worked-out example. Curriculum developers have created inventories of troubleshooting tasks that present students with incorrect solutions and require them to detect, explain and correct the error (Hieggelke et al., 2006). Yerushalmi et al. (2012) studied pairs of students engaged in a troubleshooting online activity. In the first stage of the activity students were asked to identify the misused concept or principle and explain how it conflicted with the scientifically acceptable view. In the second stage students were asked to compare their own diagnosis with an expert diagnosis provided by the online system to ascertain whether they had recognized the misused concept and clarified how the mistaken solution conflicted with the correct one. The findings indicated that pairs of students working on these activities engaged in discussions regarding the distinction between scientifically acceptable interpretations of concepts and their own interpretations, and were able to identify features of 
the concept needed to interpret it accurately. In other words, these activities focus students' attention on criteria for evaluating conflicting interpretations. Such activities can thus also develop diagnostic learning skills that can lead students to generate ARCs when engaged in subsequent self diagnosis tasks. Future research could examine the effect of such activities on students' tendencies and skills to engage in self-repair when self-diagnosing their solutions.

\section{Acknowledgements}

We wish to thank the high school physics teachers who gave their valuable time to participate in this study. We appreciate the support of the Weizmann Institute of Science, Department of Science Teaching, and The Academic Arab College for Education in Israel.

\section{REFERENCES}

Aleven, V. A. W. M. M., \& Koedinger, K. R. (2002). An effective metacognitive strategy: Learning by doing and explain with a computer-based Cognitive Tutor. Cognitive Science, 26, 147-179. doi:10.1207/s15516709 $\operatorname{cog} 2602 \_1$

Atkinson, R. K, Derry, S. J., Renkl, A., \& Wortham, D. W. (2000). Learning from examples: Instructional principles from the worked examples research. Review of Educational Research, 70, 181-214.

Atkinson, R. K., Renkl, A., \& Merrill, M. M. (2003). Transitioning from studying examples to solving problems: Effects of self-explanation prompts and fading worked-out examples. Journal of Educational Psychology, 95, 774-783. doi:10.1037/0022-0663.95.4.774

Bereiter, C., \& Scardamalia, M. (1989). Intentional learning as a goal of instruction. In L. B. Resnick (Ed.), Knowing, learning, and instructtion: Essays in honor of Robert Glaser (p. 361). Hillsdale, NJ: Lawrence Erlbaum Associates.

Catrambone, R. (1998). The subgoal learning model: Creating better examples so that students can solve novel problems. Journal of Experimental Psychology: General, 127, 355-376. doi:10.1037/0096-3445.127.4.355

Chandler, P., \& Sweller, J. (1991). Cognitive load theory and the format of instruction. Cognition and Instruction, 8, 293-332. doi:10.1207/s1532690xci0804_2

Chandler, P., \& Sweller, J. (1992). The split-attention effect as a factor in the design of instruction. British Journal of Educational Psychology, 62, 233-246. doi:10.1111/j.2044-8279.1992.tb01017.x

Chi, M. T. H. (2000). Self-explaining expository texts: The dual processes of generating inferences and repairing mental models. In R. Glaser (Ed.), Advances in Instructional Psychology (pp. 161-238). Mahwah, NJ: Lawrence Erlbaum Associates.

Chi, M. T. H., Bassok, M., Lewis, M. H., Reimann, P., \& Glaser, R. (1989). Self-explanations: How students study and use examples in learning to solve problems. Cognitive Science, 13, 145-182. doi:10.1207/s15516709 $\operatorname{cog} 1302$ _ 1

Chi, M. T. H., de Leeuw, N., Chiu, M. H., \& LaVancher, C. (1994). Eliciting self-explanations improves understanding. Cognitive Science, $18,439-477$.

Chi, M. T. H., \& VanLehn, K. A. (1991). The content of physics self-explanations. The Journal of the Learning Sciences, 1, 69-105. doi:10.1207/s15327809jls0101_4

Clark, R. C., Nguyen, F., \& Sweller, J. (2006). Efficiency in learning: Evidence-based guidelines to manage cognitive load. San Francisco: Pfeiffer.

Cohen, E., Mason, A., Singh, C., \& Yerushalmi, E. (2008). Identifying differences in diagnostic skills of physics students: Students' self-diagnostic performance given alternative scaffolding. 2008 Proceedings of the Physics Education Research Conference (pp. 99-102). Edmonton: AIP.

Crippen, K. J., \& Earl, B. L. (2005). The impact of web-based worked examples and self-explanation on performance, problem solving, and self-efficacy. Computers \& Education, 49, 809-821. doi:10.1016/j.compedu.2005.11.018

Dkeidek, I., Hofstien, A., \& Mamlouk, R. (2011). Effect of culture on high-school students' question-asking ability resulting from an inquiry-oriented chemistry laboratory. International Journal of Science and Mathematics Education, 9, 1305-1331. doi:10.1007/s10763-010-9261-0

Eilam, B. (2002). Passing through a western-democratic teacher education: The case of Israeli-Arab teachers. Teacher College Record, 104, 1656-1701. doi:10.1111/1467-9620.00216

Elby, A. (2001). Helping physics students learn how to learn. American Journal of Physics, Physics Education Research Supplement, 69, S54-S64.

Etkina, E., Van Heuvelen, A., White-Brahmia, S., Brookes, D. T., Gentile, M., Murthy, S., Rosengrant, D., \& Warren, A. (2006). Developing and assessing student scientific abilities. Physical Review. Special Topics, Physics Education Research, 2, 020103. doi:10.1103/PhysRevSTPER.2.020103

Eylon, B., \& Helfman, J. (1982). Deductive and analogical problemsolving processes in physics. New York: American Educational Research Association (AERA).

Gick, M. L., \& Holyack, K. J. (1983). Schemainduction and analogical transfer. Cognitive Psychology, 15, 1-38. doi:10.1016/0010-0285(83)90002-6

Große, C. S., \& Renkl, A. (2007). Finding and fixing errors in worked examples: Can this foster learning outcomes? Learning and Instruction, 17, 612-634. doi:10.1016/j.learninstruc.2007.09.008

Halloun, I. A., \& Hestenes, D. (1985). Common sense concepts about motion. American Journal of Physics, 53, 1056-1065. doi:10.1119/1.14031

Hausmann, R. G. M., \& Chi, M. T. H. (2002). Can a computer interface support self-explaining? Cognitive Technology, 7, 4-14.

Hausmann, R. G. M., \& VanLehn, K. (2007). Explaining self-explaining: A contrast between content and generation. In R. Luckin, K. R. Koedinger, \& J. Greer (Eds.), Artificial intelligence in education: Building technology rich learning contexts that work (Vol. 158, pp. 417-424). Amsterdam: IOS Press.

Heller, P., \& Hollbaugh, M. (1992). Teaching problem solving through cooperative grouping. Part 2: Designing problems and structuring groups. American Journal of Physics, 60, 637-645. doi:10.1119/1.17118

Henderson, C., \& Harper, K. A. (2009). Quiz corrections: Improving learning by encouraging students to reflect on their mistakes. The Physics Teacher, 47, 581-586. doi:10.1119/1.3264589

Hieggelke, C. J., Maloney, D. P., O’Kuma, T. L., \& Kanim, S. (2006). E\&M TIPERs: Electricity \& magnetism tasks. Boston, MA: Addison Wesley.

Kalyuga, S., Ayres, P., Chandler, P., \& Sweller, J. (2003). The expertise reversal effect. Educational Psychologist, 38, 23-31. doi:10.1207/S15326985EP3801_4

Labudde, P., Reif, F., \& Quinn, L. (1988). Facilitation of scientific concept learning by interpretation procedures and diagnosis. International Journal of Science Education, 10, 81-98. doi:10.1080/0950069880100108

Maloney, D. (2011). An overview of physics education research on problem solving. Getting Started in PER (Vol. 2). URL (last checked 1 May 2012).

http://www.compadre.org/Repository/document/ServeFile.cfm?ID=1 $1457 \&$ DocID $=2427$

Mason, A., Cohen, E., Singh, C., \& Yerushalmi, E. (2009). Self-diagnosis, scaffolding and transfer: A tale of two problems. In M. Sabella, C. Henderson, \& C. Singh (Eds.), 2009 Physics Education Research Conference (pp. 27-30). Ann Arbor, MI: AIP.

Mason, A., Cohen, E., Yerushalmi, E., \& Singh, C. (2008). Identifying differences in diagnostic skills between physics students: Developing a rubric. In L. Hsu, C. Henderson, \& M. Sabella (Eds.), 2008 Proceedings of the Physics Education Research Conference (pp. 147150). Edmonton: AIP.

Mazur, E. (1997). Peer instruction: A user's manual. Upper Saddle River, NJ: Prentice Hall. 
McDermott, L. C., Shaffer, P. S., \& The Physics Education Group at the University of Washington (1998). Tutorials in introductory physics (Preliminary Ed.). Upper Saddle River, NJ: Prentice Hall.

Redish, E., Saul, J., \& Steinberg, R. (1998). Student expectations in introductory physics. American Journal of Physics, 66, 212-224. doi:10.1119/1.18847

Reif, F., \& Scott, L. (1999). Teaching scientific thinking skills: Students and computers coaching each other. American Journal of Physics, 67, 819-831. doi:10.1119/1.19130

Renkl, A. (1997). Learning from worked-out examples: A study on individual differences. Cognitive Science, 21, 1-29. doi:10.1207/s15516709cog2101_1

Renkl, A., Stark, R., Gruber, H., \& Mandl, H. (1998). Learning from worked-out examples: The effects of example variability and elicited self-explanations. Contemporary Educational Psychology, 23, 90-108. doi:10.1006/ceps.1997.0959

Reisslein, J., Atkinson, R. K., Seeling, P., \& Reisslein, M. (2006). Encountering the expertise reversal effect with a computer-based environment on electrical circuit analysis. Learning and Instruction, 16, 92-103. doi:10.1016/j.learninstruc.2006.02.008

Schwartz, D. L., \& Martin, T. (2004). Inventing to prepare for learning: The hidden efficiency of original student production in statistics instruction. Cognition \& Instruction, 22, 129-184.

doi:10.1207/s1532690xci2202_1

Sokoloff, D. R., \& Thornton, R. K. (2001). Interactive lecture demonstrations. New York, NY: Wiley.

Sweller, J., van Merriënboer, J. J. G., \& Paas, F. G. (1998). Cognitive architecture and instructional design. Educational Psychology Review, 10, 251-296. doi:10.1023/A:1022193728205

Tamir, P., \& Caridin, H. (1993). Characteristics of the learning environment in biology and chemistry classes as perceived by Jewish and Arab high school students in Israel. Research in Science and Technological Education, 11, 5-14. doi:10.1080/0263514930110102
Van Gog, T., Paas, F., \& van Merriënboer, J. J. G. (2008). Effects of studying sequences of process-oriented and product-oriented worked examples on troubleshooting transfer efficiency. Learning and Instruction, 18, 211-222. doi:10.1016/j.learninstruc.2007.03.003

Viennot, L. (1979). Spontaneous reasoning in elementary dynamics. European Journal of Science Education, 1, 205-221. doi: 10.1080/0140528790010209

Ward, M., \& Sweller, J. (1990). Structuring effective worked examples. Cognition and Instruction, 7, 1-39. doi:10.1207/s1532690xci0701 1

Wertsch, J. V. (1984). The zone of proximal development \& some conceptual issues. In B. Rogoff \& J. V. Wertsch (Eds.), Children's learning in the "zone of proximal development"-New directions for child development (pp. 7-18). San Francisco: Jossey-Bass.

Yerushalmi, E., Henderson, C., Heller, K., Heller, P., \& Kuo, V. (2007). Physics faculty beliefs and values about the teaching and learning of problem solving part 1: Mapping the common core. Physical Review Special Topics-Physics Education Research, 3, 020109. doi:10.1103/PhysRevSTPER.3.020109

Yerushalmi, E., Mason, A., Cohen, E., \& Singh, C. (2009). Self-diagnosis, scaffolding and transfer in a more conventional introductory physics problem. In M. Sabella, C. Henderson, \& C. Singh (Eds.), 2009 Physics Education Research Conference (pp. 23-27). Ann Arbor, MI: AIP.

Yerushalmi, E., Puterkovski, M., \& Bagno, E., (2012). Knowledge integration while interacting with an online troubleshooting activity, Journal of Science Education and Technology. doi:10.1007/s10956-012-9406-8

Yerushalmi, E., Singh, C., \& Eylon, B. (2007). Physics learning in the context of scaffolded diagnostic tasks (1): The experimental setup. In L. McCullough, L. Hsu, \& C. Henderson (Eds.), Proceedings of the Physics Education Research Conference (pp. 27-30). Greensboro, NC: AIP. 